\title{
UM OLHAR PARA MULHERES IDOSAS: RELATO DE UMA EXPERIÊNCIA DE INTERVENÇÃO
}

\author{
Marly Lamb* \\ Meyre Eiras de Barros Pinto \\ Jeanette Monteiro De Cnop"
}

RESUMO. O presente artigo é resultado de um projeto de intervenção realizado com quarenta e oito mulheres idosas que participam de um grupo de convivência. As atividades desenvolvidas tiveram como objetivo propiciar trocas de experiências buscando oportunizar um maior crescimento subjetivo às idosas, bem como a construção da percepção de si mesmas enquanto membros de um grupo, com vistas a ressaltar a importância do idoso no contexto do desenvolvimento sociocultural.

Palavras-chave: idoso, qualidade de vida, grupo de convivência.

\section{ELDERLY WOMEN IN THE LIMELIGHT: REPORT ON AN INTERVENTION EXPERIENCE}

\begin{abstract}
This article is the result of a project of intervention carried out with forty-eight elderly women who took part in an acquaintanceship group. Developed activities offered the participants opportunity to exchange experiences. The latter provided a subjective development to the group and the construction of their own perception as group members. At the same time the importance of old people in a context of social-cultural development was highlighted.
\end{abstract}

Key words: elderly, quality of life, acquaintanceship group.

\footnotetext{
* Professora assistente do Departamento de Psicologia da Universidade Estadual de Maringá. Endereço para correspondência: Departamento de Psicologia, Universidade Estadual de Maringá, Av. Colombo, 5790, CEP 87020-900, Maringá-Paraná.

* Professora adjunta do Departamento de Psicologia da Universidade Estadual de Maringá.

ฯ Professora adjunta do Departamento de Letras da Universidade Estadual de Maringá

\begin{tabular}{|l|l|l|l|l|l|}
\hline Psicologia em Estudo & DPI/CCH/UEM & v. 5 & n. 1 & p. $105-113$ & 2000 \\
\hline
\end{tabular}
}




\section{INTRODUÇÃO}

Conhecer as características de uma população a ser trabalhada é obrigatoriedade, no sentido de se elaborar uma abordagem adequada. Portanto, em uma proposta de trabalho educativo para o envelhecimento não se podem desprezar as transformações demográficas, tecnológicas e pessoais.

No Brasil, o crescimento do número de idosos tem sido gradual e em ritmo similar à maioria dos países subdesenvolvidos. Conforme dados do IBGE, a população com 65 anos e mais, em 1940, era de 2,38\% (equivalente a 980 mil), e saltou em 1991 para 4,83\% (7.086 milhões). A projeção, segundo a mesma fonte, é que passe a 5,12\% em 2000 (8.658 milhões aproximadamente), 5,83\% em 2010 (11.192 milhões) e 7,64\% em 2020 (16.224 milhões). (Berquó, 1999)

Esse aumento significativo é decorrente de mudanças que têm ocorrido, tanto no que se refere aos níveis de natalidade (redução de número de filhos) quanto aos de aumento da longevidade, decorrente do avanço da tecnologia (prevenção e eliminação de doenças; controle sobre moléstias infecto-contagiosas e epidemias). Contudo, embora a ciência tenha conseguido estender significativamente a expectativa de vida das pessoas, ainda se faz necessário que sejam viabilizadas condições para que estas tenham uma existência digna, representada por uma boa qualidade de vida e por um bem-estar psicológico e social na velhice.

Neri (1993) e Neugarten (1979), entre outros, caracterizam o processo de envelhecimento como uma fase de transformações biológicas, psicológicas e sociais. Debert (1998 e 1999) enfatiza que a velhice não é uma categoria natural, mas sim um processo que é elaborado simbolicamente e que varia de cultura para cultura. Para ela, deve-se ressaltar a importância do respeito à heterogeneidade destas transformações, uma vez que os estereótipos sociais estabelecem a homogeneização da velhice como um período de isolamento, em função da doença, da pobreza, da dependência, da passividade e de sentimentos de solidão, ou seja, de comportamentos e de emoções iguais para todos os idosos.

Segundo Neri (1993 e 1999), os elementos determinantes do bem-estar na velhice são: saúde mental e biológica, eficácia e controle cognitivo, produtividade, atividade, renda, continuidade de papéis familiares, ocupacionais, e de relacionamentos informais em grupos primários, entre outros. Com isso, o envelhecer satisfatoriamente está 
diretamente relacionado à busca de equilíbrio entre as limitações impostas pelas perdas e à utilização das potencialidades restantes. No entanto, a boa qualidade de vida e o bem-estar psicológico e biológico na velhice não são apenas responsabilidade do indivíduo, mas também decorrem de condições estabelecidas nas relações socioculturais.

Uma grande verdade é que, com a evolução sociodemográfica da população brasileira, a maioria dos idosos, no futuro, sobreviverá em centros urbanos. Por isso, os grupos de convivência, enquanto espaços e oportunidades para a educação informal, passam a ter um papel relevante na melhoria da qualidade de vida dos idosos, pois propiciam recursos para manter uma vida mais autônoma e independente. Nesse sentido, Neri e Cachioni (1999), dizem: “as oportunidades educacionais são apontadas como importantes antecedentes de ganhos evolutivos na velhice, porque, acredita-se, elas intensificam os contatos sociais, a troca de vivências $e$ de conhecimentos e o aperfeiçoamento pessoal"(p.115).

Envolvidas com essa questão, as autoras deste trabalho desenvolveram, por um período de dois anos, juntamente com acadêmicas do curso de Psicologia ${ }^{1}$, atividades de intervenção em um grupo de convivência denominado "Idade Feliz". Os objetivos do projeto foram: auxiliar na melhoria da qualidade de vida, no processo de conscientização dos problemas sociais e psicológicos, vinculados ao envelhecer, e propiciar condições para restaurar no grupo de idosas sentimentos de eficácia e de importância para o contexto social.

\section{METODOLOGIA}

Como este Projeto de Extensão envolveu, simultaneamente, estudo, pesquisa e intervenção, há necessidade de serem destacadas diferentes metodologias.

Quanto ao grupo de estudos, sempre se teve por escopo a formação de profissionais para atuarem na área, promovendo-se atividades que permitissem a aquisição de conhecimentos, de maneira que se pudesse avançar teoricamente e discutir o cotidiano dessas acadêmicas, suas inserções/ações enquanto cidadãs e profissionais, objetivando uma prática futura. Seminários, leituras individuais e

Adriana Moreno Palacio; Constanza Pujals; Fernanda Barbosa Lima; Priscila Frederich; Renata de Fátima Almeida; Renata de Silva e Silvana Pedro Pinto. 
discussões em grupo abordaram “dados epistemológicos, aspectos psicológicos, biológicos e sociais do envelhecimento, importância e necessidade de atividades, religiosidade, relação velho X sociedade” e outros.

No que se refere à pesquisa, considerando-se a necessidade de estabelecer a caracterização, o perfil das senhoras e as representações que faziam da etapa de vida em que se encontram, para subsidiar as atividades de intervenção no grupo, foram realizadas entrevistas estruturadas, com as integrantes do grupo (48 senhoras). Essas entrevistas permitiram uma análise quantitativa e qualitativa. Posteriormente procedeu-se à aplicação de um instrumento, o Diferencial Semântico de Osgood e cols. (1957) modificado por Neri e cols. (1991) e sintetizado, contendo vinte e oito (28) pares de adjetivos antônimos. A atividade requerida era que assinalassem cinco desses adjetivos, dispostos aleatoriamente na primeira ou na segunda coluna, tomados com a valorização positivo ou negativo, que mais se adequassem às categorias apresentadas: "Eu me considero" e "O idoso costuma ser". Através desse instrumento pretendia-se alcançar uma apreensão das representações que as senhoras faziam de si mesmas e da velhice em geral.

No tocante ao terceiro aspecto, intervenção, a equipe, com a intenção de auxiliar na melhoria da qualidade de vida dessas senhoras, organizou discussões que propiciassem o processo de conscientização de problemas sociais, psicológicos e afetivos, vinculados ao envelhecer. Para tal atividade buscou-se, inicialmente, conhecer os temas de seu interesse, ou seja: fases do desenvolvimento, saúde física e mental, relações sociais e familiares, o papel da mulher na sociedade, problemas do cotidiano e experiências vividas, conflito intergeracional e políticas de saúde na terceira idade, entre outros.

A equipe utilizou técnicas de dinâmica de grupo e de discussões, que ocorreram tanto sob o enfoque da área de Psicologia quanto no que se refere ao uso da linguagem, com a exploração de textos, filme, música, buscando subsidiar as discussões através do exercício do diálogo, de produção de textos em equipes e atividades outras que permitissem uma gradativa ampliação da "visão do mundo" e de "si mesmas". 


\section{RESULTADOS}

No que se refere às atividades desenvolvidas no grupo de estudos, foi avaliado positivamente o resultado das leituras, das discussões, tendo em vista o crescimento e o aprofundamento teórico-científico sobre a temática para subsidiar a prática psicológica.

Esta atividade foi especialmente importante para as acadêmicas, em vista da ausência, na grade curricular do curso de Psicologia, de uma disciplina específica de Psicologia do Envelhecimento.

Como resultado das atividades de pesquisa, pôde ser estabelecido o perfil do grupo. Trata-se de uma população diferenciada, com bom nível socioeconômico, comparando-se com a maioria dos idosos brasileiros. São independentes, ativas e estabelecem vínculos sociais além da participação no programa.

Com vistas a complementar esse perfil com informações relativas a visão de mundo, sentimentos, projeto de vida futura, os quais subsidiaram a metodologia de intervenção, foram encontrados núcleos temáticos na análise qualitativa.

Quanto a relacionamento conjugal, prevalecem no grupo senhoras viúvas (24) e casadas (20). Três são separadas e apenas uma solteira. Dessas, 14 viúvas, duas separadas e a solteira não se manifestaram. A maioria das que responderam ao item (81\%) qualifica positivamente os relacionamentos com seus maridos, no presente ou no passado, dando ênfase à igualdade do casal, tanto nos papéis sociais quanto nas tomadas de decisão. Ressalte-se que a intimidade e o companheirismo no relacionamento são fatores determinantes da avaliação delas.

No núcleo temático significado de velhice, a maioria (58\%) tem uma concepção positiva, pois a percebem como um processo tanto natural do curso de vida quanto gerador de perdas e ganhos decorrentes de aspectos biológicos, psicológicos e sociais.

Quanto à forma como a sociedade vê o idoso, a quase totalidade das senhoras (87\%) se remeteu aos aspectos negativos vinculados aos estereótipos, à perda da autonomia, à exclusão, ao desrespeito e à desvalorização, entre outros.

No que se refere à qualidade de vida nestes últimos anos, $75 \%$ avaliou positivamente este quesito, atribuindo-o a uma maior liberdade obtida com a idade, a oportunidade de fazer o que gosta, o tempo livre, a 
autonomia, a tranqüilidade financeira obtida com a aposentadoria e a desobrigação do cuidado com os filhos. Entre as que avaliaram negativamente, $17 \%$ mencionaram fatores financeiros e falta de companheiros, dos filhos, de ter o que fazer, e a solidão. Quatro referem não terem percebido mudança.

Perguntadas se abrigavam sentimento de solidão, a metade respondeu que não. Algumas (19\%) disseram se sentirem sós esporadicamente, e as que responderam afirmativamente relacionaram isto a problemas de saúde, ausência de filhos e falta de atividade.

Sobre projetos futuros, a maioria (73\%) apresentou projetos pessoais vinculados a: busca de conhecimentos e continuidade de desenvolvimento, posse de bens materiais, manutenção da saúde, entre outros, e projetos vinculados aos filhos e netos. Uma parte (27\%) mencionou a inexistência de projetos para o futuro, enquanto três (6\%) se consideraram realizadas.

Finalmente, em razões para participar de grupos de convivência, a maioria apontou os vínculos afetivos, as trocas de experiências, as oportunidades de lazer e distração. Também foram mencionadas outras razões: convivência com pessoas da mesma coorte etária, exercícios físicos, etc.

Da análise do Diferencial Semântico de Osgood e cols. (1957) obteve-se, como resultado, que em "Eu me considero" sobressaem valores positivos, com as ocorrências marcadas aqui entre parênteses: construtivo (19), esperançoso (12), alegre (10), independente (9), carinhoso (9), interessado pelas pessoas (9), fácil de contentar (7), sociável (6), seguro (6), generoso (6), saudável (5), discreto (5), humilde (5), forte (5), atualizado (4), útil (4) e valorizado (4). Em contrapartida, os valores negativos são pouco mencionados: exigente (5) e desconfiado (4).

Em "O idoso costuma ser" os valores positivos têm freqüência bem menor: sábio (8), humilde (8), fácil de contentar (6), alegre (5), carinhoso (5), esperançoso (4), conformado (4). Os valores negativos prevalecem: exigente (11), triste (10), isolado (10), queixoso (9), dependente (8), distraído (7), desconfiado (6), inseguro (6), confuso (6), desvalorizado (5), fraco (4), doentio (4).

Quando se referem a si mesmas, os valores negativos não são indesejáveis no nosso tempo presente, ou seja, ser exigente e desconfiado é próprio de quem sabe lutar pelos próprios direitos. 
Nas considerações sobre a velhice em geral, os valores positivos justamente contrariam esse conceito. Alguém humilde, fácil de contentar, alegre, carinhoso, esperançoso, conformado, é alguém fácil de se manipular, sem "garra” para lutar, apesar de sábio. Enquanto tinham de si uma imagem positiva, demonstravam estar incorporando os estereótipos que a sociedade tem da velhice.

Extrapolando o caráter de pesquisa que se atribuiu à aplicação deste instrumento, o cômputo dos dados bem como o que deles se pôde inferir foi objeto de reuniões entre todas as profissionais e as acadêmicas, que planejaram a devolução dos resultados ao grupo de idosas, as quais se mostraram perplexas por terem incorporado os estereótipos vigentes na sociedade, e suas reflexões a partir daí resultaram muito ricas, passando a separar o conceito de pessoas idosas, em geral, do de pessoas doentes e dependentes.

Como resultado das atividades de intervenção, observou-se: a) um maior crescimento subjetivo das idosas, no que se refere à valorização da auto-estima, à percepção do próprio corpo, à diminuição de dificuldades na expressão de emoções, na afetividade e nas trocas de experiências; b) uma melhoria na percepção de si mesmas enquanto membros de um grupo, o que as levou a se conscientizarem da necessidade de se tornarem agentes de transformação na sociedade, exigindo e instituindo direitos enquanto cidadãs.

Como resultado da produção de textos, também o espírito de equipe foi trabalhado, com as atividades de redação cooperativa. Com a preocupação sempre presente de atingir um locutor real, e de trabalhar em situações de real interação, as participantes do projeto puderam experenciar a alegria de se sentirem capazes de construir, através da linguagem. Perceberam-se como produtoras de textos, conforme externaram.

\section{CONCLUSÃO}

Apesar de algumas dificuldades encontradas em função da característica da população de idosas (diferenças de interesses, de escolaridade, de objetivos para integração no grupo, entre outros), a equipe percebeu mudanças qualitativamente positivas nessas senhoras, no que se refere à percepção de si e do outro, à auto-estima, à integração individual x grupal; em essência, uma nova inserção dessas 
idosas na sociedade, possibilitando uma melhoria na qualidade de suas vidas. Nesse sentido, acredita-se ter atingido os objetivos propostos, apesar de se considerar a longa jornada que estas mulheres têm a sua frente, uma vez que a construção da cidadania vai sendo paulatinamente realizada.

Quanto à relação ensino/pesquisa/extensão, torna-se cada vez mais necessária a implantação e a consolidação de linhas de pesquisa acerca do tema envelhecimento. A equipe reafirma a necessidade de conhecimentos teóricos aprofundados nas áreas de Psicologia, Educação, Linguagem, entre outras, que só podem ser obtidos pela pesquisa e pela aprendizagem, para a compreensão do sujeito objeto da intervenção.

Extrapolando o âmbito deste estudo, vale ressaltar que a participação das mulheres idosas em grupos de convivência tem, no geral, em sua essência, o objetivo de lazer, visando às trocas de experiências, à formação de vínculos afetivos/sociais, à diminuição da solidão, mas suas ações e razões de freqüência não têm conseguido ultrapassar os limites dos objetivos individuais. A perspectiva da equipe de intervenção, neste trabalho, era de que, apesar de considerar e respeitar a existência de diferenças e motivações individuais, as atividades desenvolvidas junto a estas senhoras poderiam e deveriam também atingir objetivos coletivos. Seria desejável que estas reflexões fizessem parte das discussões presentes nesses grupos de convivência e em outros trabalhos de caráter educativo com a terceira idade.

\section{REFERÊNCIAS BIBLIOGRÁFICAS}

Berquó, E. (1999). Considerações sobre o envelhecimento da população no Brasil. Em A. L. Neri \& G. G. Debert (Orgs.). Velhice e Sociedade. (pp. 1140). Campinas: Papirus.

Debert, G.G. (1998). A antropologia e o estudo dos grupos e das categorias de idade. Em M. M. L. Barros (Org.). Velhice ou Terceira Idade. Estudos antropológicos sobre identidade, memória e política. (pp. 49-67). Rio de Janeiro: Editora Fundação Getúlio Vargas.

Debert, G. G. (1999). A construção e a reconstrução da velhice: família, classe social e etnicidade. Em A. L. Neri \& G. G. Debert (Orgs.) Velhice e Sociedade.(pp. 41-48). Campinas: Papirus.

Neri, A. L. (1991). Envelhecer num país de jovens: significados de velho e velhice segundo brasileiros não idosos. Campinas: Unicamp. 
Neri, A. (Org.). (1993). Qualidade de vida e idade madura. Campinas: Papirus.

Neri, A. \& Cachioni, M. (1999).Velhice bem-sucedida e educação. Em A.L. Neri \& G. G. Debert. Velhice e Sociedade. (pp. 113-140). Campinas: Papirus.

Neugarten, B. L. (1979). Time, age and life cycle. American Journal of Psychiatry, 136, 7, 887-94.

Recebido em 02/02/00

Revisado em 18/04/00 Aceito em 20/04/00 